\title{
Lessons from the welding booth: theories in practice in vocational education
}

\author{
Stig-Börje Asplund ${ }^{*}$ and Nina Kilbrink
}

\author{
*Correspondence: \\ stig-borje.asplund@kau.se \\ Department of Educational \\ Studies, Karlstad University, \\ Karlstad, Sweden
}

\begin{abstract}
This article reports results from a Learning study in which two university based researchers collaborate with a vocational teacher at an upper secondary vocational school. During three iterative cycles, two different theories (Conversational Analysis and Variation Theory) have gradually been incorporated when teaching how to TIG-weld. Through concrete empirical examples from video recorded lessons the article explores how these theoretical perspectives (termed CAVTA) can be used together and integrated in practice when analysing the teaching and learning processes that take shape when teacher and students interact in relation to the object of learning to T/G-weld, and how these theories can be used as didactical tools. The analyses highlights concrete changes in the teacher's teaching, and it is argued that the approach used in the study can lead to a development where we can find forms for teaching specific subject content within vocational education.
\end{abstract}

Keywords: Learning study, Teachers' professional learning, Conversation Analysis, Variation Theory, Vocational education, Welding, CAVTA

\section{Introduction}

Educational research has for a long time, and from various angles, been criticised for fairly unilaterally researching teachers and their activities, rather than allowing them to be involved in the research process as such. In parallel with this, practice-based school research has been requested in research, and aiming for developing teacher's teaching on a scientific basis and putting theories into practice has been an area of focus in steering documents as well in research (cf. Brante et al. 2015; Carlgren 2017; Lo 2012; SFS 2010: 800). Over the past decade, however, one can see a development where teachers are increasingly involved in research, and where they, together with researchers, focus on issues that the school and its teachers have been involved in formulating (Ko 2018; Postholm 2018). In this work, action research studies in iterative circles such as Learning studies have been identified as effective approaches for teachers to change and develop their teaching practices, as well as improving student learning (cf. Marton and Ling 2007; Pang and Ling 2012; Timperley 2011). According to Lo (2012) theories need to be tested in practice in order to see how they can be useful for teachers to improve teaching and learning. Furthermore, Lo argues that Learning studies need to be developed in more subject areas than what has been previously been done and also stresses the 
importance of targeting "objects of learning outside of the cognitive domain" (p. 198), which has not yet been done so much. One of these research fields where there is a lack of Learning studies, and where issues of subject content is significantly absent is within the field of vocational education.

In technical vocational education, the learning content in program specific subjects are to a high extent handled in the interaction between teacher and students (Filliettaz 2011; Sakai et al. 2014). Despite this, there is a significant lack of studies focusing on how a specific vocational learning content is taught and learned when vocational teachers and vocational students interact in a vocational education context. Most studies that examine the practices of the vocational classrooms tend to focus more on general pedagogical issues such as how meaning is negotiated between teachers and students, and what communicative strategies teachers and students use when interacting with each other in teaching and learning situations (Khaled et al. 2016; Schaap et al. 2017), while questions about the specific content to be learned have been of less interest (however, see Asplund and Kilbrink 2018; Kilbrink and Asplund 2018, for some exceptions). Furthermore, in order to keep quality of vocational education, vocational teachers need to get opportunities to develop professionally during their professional working lives as teachers (cf. Andersson and Köpsén 2015; Serafini 2018). However, research in the area of vocational teachers' professional development is rare, and even fewer studies focus on how to improve the actual teaching of a specific vocational learning content at school, and the teaching and learning process in the vocational workshop (cf. Asplund and Kilbrink 2018; Lucas et al. 2012). This study aims to fill this rather acute gap of concrete and empirical studies focusing on the teaching and learning of specific subject content that emerges when teacher and students interact in vocational education classrooms. Previous studies have proven the Learning study to be an efficient method for developing professionally as a teacher when teaching a specific learning content (e.g. Pang and Ling 2012), and we have chosen to use this method in relation to welding teaching. A key result from previous Learning studies is that students' learning is facilitated by making the learning content visible through variation (cf Lo 2012; Lo and Marton 2012). We will therefore not study if the students' learning increases, but focus on how to make the learning content visible. We will also not focus on questions about how one should or how one can weld in the best way. Our interest is instead directed to questions concerning how to create conditions for learning to weld to take place when a teacher and students interact in vocational education classrooms.

In this article, we will highlight results from a Learning study which involves a close cooperation between two university based researchers, and one vocational teacher at an upper secondary vocational school in Sweden. ${ }^{1}$ During the process of three iterative cycles that lasted for a year, theories have gradually been incorporated into the welding teaching, in dialogue with the teacher. Through a close and detailed analysis of the learning processes that take place when the vocational teacher and upper secondary students interact in relation to the object of learning the specific welding method TIG-weld, we will show not only what happens when theories get tested and used in practice, but also

${ }_{1}^{1}$ Learning to weld in vocational education, financed by the Swedish Institute for Educational Research (Ref no 2017 00056). 
how such an approach improves the teaching regarding the content that the students are supposed to learn. In this specific welding method it is important to create a weld pool in which the metal melts, which we refer to as the melt. Thus, one of the things that the students are supposed to learn in order to TIG-weld and that is crucial in the welding act is making the melt. This was also something that emerged in the data during the Learning study and therefore, in this article, we have chosen to focus on how the melt is made relevant in the interaction during three iterative cycles. More precisely, the aim of this article is to explore how the teacher's orientation towards the critical aspect the melt when teaching how to TIG-weld changes during three iterative cycles when participating in a Learning study.

\section{Theories and methodology}

In this study, we use Conversation Analysis (CA) together with Variation Theory (VT) as a basis for the teaching, and as a tool for analysing the teaching and learning. When combining these theories we use the abbreviation CAVTA (Conversation Analysis and Variation Theory Approach). Those theories have previously been used together when analysing learning processes in school contexts (Asplund and Kilbrink 2018; Emanuelsson and Sahlström 2008; Kilbrink and Asplund 2018), but in this article we go one step further and integrate them into CAVTA. Our approach is in line with the content centred CA-studies that aim to capture interactional practices linked to learning a specific content or practice (cf. Rusk et al. 2015). This means that the focus in our analysis is on how the teacher and the students orient to the specific object of learning of how to TIG-weld, and how the teacher and students adapt and change their participation in the unfolding interaction regarding how to TIG-weld, where the VT can help us understand the enacted object of learning in great detail. Before we present the results of the study, some words about CA and VT would be in place.

\section{Conversation Analysis}

The starting point for our work on integrating the Conversation Analysis with the Variation Theory and to let CAVTA be a teaching theory for the teacher, as well as analytical tools in the analysis of the executed teaching, is the contemporary notion in conversation analytic research that learning is constituted in interaction between participants, and between participants and artifacts in surrounding contexts (see, for example, Melander and Sahlström 2010; Sahlström 2011). This approach has a lot in common with those learning theories that emphasise learning as change in participation (e.g. Lave 1993; Rogoff 2003). Thus, within CA there is an interest in how people realise meaning and understanding when interacting with each other and artefacts in the surrounding context (Drew and Heritage 2006; Goodwin 2000; Schegloff 2007) and which communicative resources (verbal as well as non-verbal) participants use in interaction (Drew and Heritage 2006; Goodwin 2000; Schegloff 2007).

A central task in CA is to identify the actions that participants carry out and to describe the specific practices of conduct that they use to accomplish them. Sidnell explains participants' work in displaying to one another their orientation to the interaction like this: 
For a practice to be effective it must be recognizable to a recipient what action a speaker means to accomplish by deploying it. For human action to be efficiently, a recipient must be able not only to recognize what action a practice meant to accomplish, but also to check that his/her understanding of it is correct, or at least sufficient. $(2013, p .78)$

For the conversation analyst, the participants' work with showing their mutual understanding of each other's actions turn by turn gives the opportunity to anchor the analysis empirically-i.e. in the participants' demonstrated understanding of the interactionand thereby the approach provides material for analytic explication (Schegloff 2007). Conversation analysts describe this in terms of taking up a radical participant perspective; what is to be studied should be found in participants' displayed orientation (cf. Sahlström 2011; Sidnell 2013).

This ambition is also something that we see as fruitful to base teaching on when trying to make students' knowing and understanding visible in the interaction with teachers here and now. If teachers, with inspiration from CA's radical participant perspective, actively work to encourage students to express (through the use of both verbal and nonverbal communication resources) their understanding and knowledge and by using the conceptual arsenal of variation theory in this work (see below) to enable clarification of what is central to the task, one can work in a systematic way to achieve a mutual understanding of what is to be learned and how it is to be learned. By offering the student such opportunities in a teaching situation, favorable conditions for a learning to take place is thus created. And it is precisely in this meeting between teacher, student and a specific content that should be learned that the two perspectives (Conversation Analysis and Variation Theory) can be used together, simultaneously and integrated as CAVTA, and thereby constitute an important teaching theory in teachers' work.

Therefore, we believe that CA should not be limited to constituting a method for studying what people do together in different activities and situations, but that it also, in a very methodical and systematic way, together with variation theory, can be used as a fundamental point of departure in teachers' work on planning, executing and evaluating their own teaching. Our approach can thus be seen as a further development and a deepening of the conversational analytic research (Applied CA) that tries to apply the conversation analysis in concrete and actual contexts (cf. Antaki 2011).

\section{Variation theory}

Variation theory is emphasised as a learning theory, which highlights the learning content as the object of learning (OoL) (cf. Marton and Tsui 2004), and it can be used in designing teaching and learning situations (cf. Lo 2012). When the OoL refers to what is possible to learn during the teaching/learning situation, it is denoted as the enacted OoL, and is what we are focusing on in this study (and not what the teacher planned for or what the students actually learned). Aspects of the OoL that are important to discern in order to learn an OoL are called critical aspects. The enacted OoL is depending on which critical aspects of the object of learning are made visible for the learners in the teaching/learning situation through variation. In order to do this, different patterns of variation can be used. For example, critical aspects can be compared to something they are not (contrasting) or different appearances of a critical aspect can be made visible 
(generalisation) (cf. Marton and Tsui 2004). When the critical aspects adopt the right value they constitute the critical features of the OoL. During a teaching situation different critical aspects can be foregrounded and backgrounded alternately, and the OoL must be considered as dynamic. This could be done between teacher and students in interaction in which both parties can initiate and influence what is highlighted in the teaching situation (cf. Asplund and Kilbrink 2018; Kilbrink and Asplund 2018). Furthermore, the OoL can be divided into a direct and an indirect OoL, where the direct OoL refers to content and indirect OoL to a capability related to the content (Lo 2012). For example-in relation to language learning the direct OoL could be a foreign language, and the indirect OoL can differ between understanding and using the foreign language.

\section{Learning study}

The data that will be presented and analysed in this article is based on an action oriented Learning study on the learning processes that emerge when a vocational teacher and upper secondary students interact with tools and materials in relation to the object of learning (OoL) to weld. The starting point for this study is a close collaboration between two university based researchers, and one vocational teacher at upper secondary school. The teaching that the teacher conducts in the classroom is planned, executed, and analysed in three iterative cycles, inspired by the Learning study method (cf. Kilbrink et al. 2014; Pang and Ling 2012). In a Learning study, there is a specific focus on the learning content (referred to as the OoL), and previously mostly based on the Variation Theory of learning. The teaching of this OoL is planned, executed and analysed in specific steps in iterative cycles; pre-testing, planning, teaching, post-testing, analysing and revising (Ko 2018). In our study, however, we use CA in combination with Variation Theory in CAVTA and in line with our interest in the process of teaching and learning how to TIG-weld, we have replaced the pre- and post-tests with tools derived from CA in order to analyse how welding competences are displayed, developed and learned in the actual teaching situations. This means that instead of conducting a test before and after the welding lesson, the teacher encourages the student to use different semiotic resources simultaneously in order to express his or her understanding of the object of learning in the teaching situation here and now.

Approaching the data also from a CA's understanding of participation and social organisation can help us to reveal the learning processes that take shape in the interaction from an emic perspective (Duranti 1997). The CA perspective can also add another dimension of how the OoL can be varied in the interaction between participants when using different semiotic resources.

In this study, the vocational teacher planned the teaching to be conducted in collaboration with the two researchers. The results from our previous studies on welding teaching (Asplund and Kilbrink 2018; Kilbrink and Asplund 2018) together with CA, Variation Theory, syllabus, and teacher as well as student needs form the basis for the planning of the teaching. Together with colleagues at the school, the teacher has for each recording occasion asked and selected three to four students who have not previously welded TIG-welding, and the teaching has subsequently been video recorded. ${ }^{2}$ Thereafter, the

\footnotetext{
$\overline{2}$ All teachers and students in this study have been informed about the aim and implementation of the study and have signed a written consent to participate.
} 


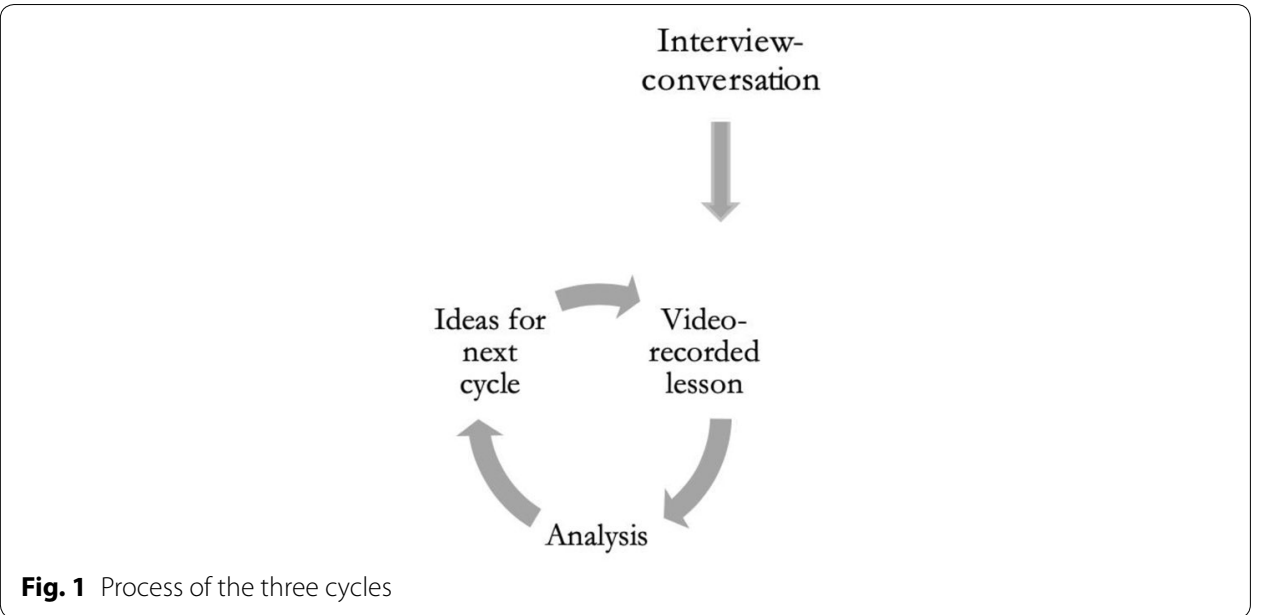

video recordings have been analysed, first by the researchers and thereafter researchers and teacher together. This procedure is repeated in three cycles, and for each new cycle the teaching is changed based on analyses and evaluations of the previous cycle (see Fig. 1). For each cycle, new students who weld TIG-welding for the first time at school participate.

\section{Context of the study and data material}

The study was conducted in the workshop at the upper secondary school in Sweden where the vocational teacher works as a teacher in welding. In this study we have focused our interest on the teaching that takes shape when students learn to TIG-weld, and therefore we have deliberately selected focus students who have not previously used the welding method. Before each cycle, new focus students have been selected, whose interaction with the teacher has been followed by a video camera.

With the camera (the teacher has also been equipped with a portable microphone to optimise the sound recording in an environment that periodically can be quite noisy), we have then followed the teacher through the entire teaching lesson when the students are taught TIG-welding for the first time at the school. During cycle 1, 122 min of video recordings, cycle 2, $73 \mathrm{~min}$ and cycle 3, $75 \mathrm{~min}$, was collected, which gives a total time of $270 \mathrm{~min}$, which is our analysis material for this study. From this material we have chosen to look more closely at the situations when the teacher orients towards the melt, which is an important aspect of TIG-welding, in the teaching and we direct our interest towards the changes that take place in the teacher's teaching in and between the three cycles.

In the analysis of the interaction we have used CAVTA and the use of detailed representations of the interaction that has been developed within CA is in this article presented in the form of detailed transcriptions of spoken data, as well as still images of visual phenomena in the interaction between the teacher and the students (see transcript notations in Appendix for transcription conventions). Below we present our analyses and their results. We will focus the analysis on the sequences of the video recorded teaching as the focus is on the orientation towards the melt as a critical aspect of making a TIG-weld. However, this will be done in relation to the overall lesson context, which 
means that in the result report below we will also describe the phases of the teaching as the melt is highlighted in the foreground in the interaction.

\section{Analysis and results}

In this section we describe the implementation of the three cycles and how the processes that are set into play when teacher and students are orienting towards the critical aspect the melt emerge in the interaction when teaching and learning how to TIG-weld. This description and analyses together constitute the results responding to the aim to explore how the teacher's orientation towards the critical aspect the melt when teaching how to TIG-weld changes during three iterative cycles when participating in a Learning study.

\section{Implementation of three cycles of teaching}

Before implementing the first cycle, the teacher read our previous research on welding (Asplund and Kilbrink 2018) and a text on variation theory (Carlgren 2017). Thereafter, an interview conversation was conducted with the vocational teacher by the two researchers, with the purpose to give the researchers some insights into the specific teaching context, and into the vocational teacher's didactic approach to the teaching of the TIG-welding method. For the first cycle, we did not go into planning the teaching in detail using the CAVTA, but rather asked the teacher to teach as he was used to (possibly influenced by the texts he had read through). The first cycle lesson was then conducted and video recorded. These recordings were analysed, by the researchers at a primary stage, then analysed by the researchers and the teaching vocational teacher together. Three students participated in this lesson. Based on these analyses, based on a CAVTA perspective, the teacher, together with the researchers, worked on new teaching strategies that were to be incorporated into the teacher's didactic approach towards cycle 2 (see Fig. 1). In this work, the researchers and the teacher collaborated on how CAVTA could be used in the teaching situations to enable clarification of what is central to the task, and as a way to achieve a mutual understanding of what should be learned and how it should be learned in the interaction here and now. The process of the second and third cycle is the same as the first one (three students participated in respective cycle as well), with the exception of the interview conversation that did not take place during the second and third cycle (see Fig. 1).

During the documented lessons, clear phases of different kinds of interaction emerge, and these phases also change during the first year when the three cycles are implemented in the teaching. In our article, however, the analyses will not focus on how the different phases per se develop, but on the interaction when it is oriented towards the melt. However, in order to contextualise the interaction that will be analysed in more detail, we briefly present the different phases and their relation to each other using Fig. 2. This figure illustrates the different phases of the teaching as they appeared during cycles 1 and 2 (see Fig. 3 for a description of the phases during cycle 3 ).

\section{Cycle 1}

In the first example (Excerpt 1A), a sequence from the first cycle from phase 1 is analysed. The teacher has just completed a longer oral instruction in which he has explained 

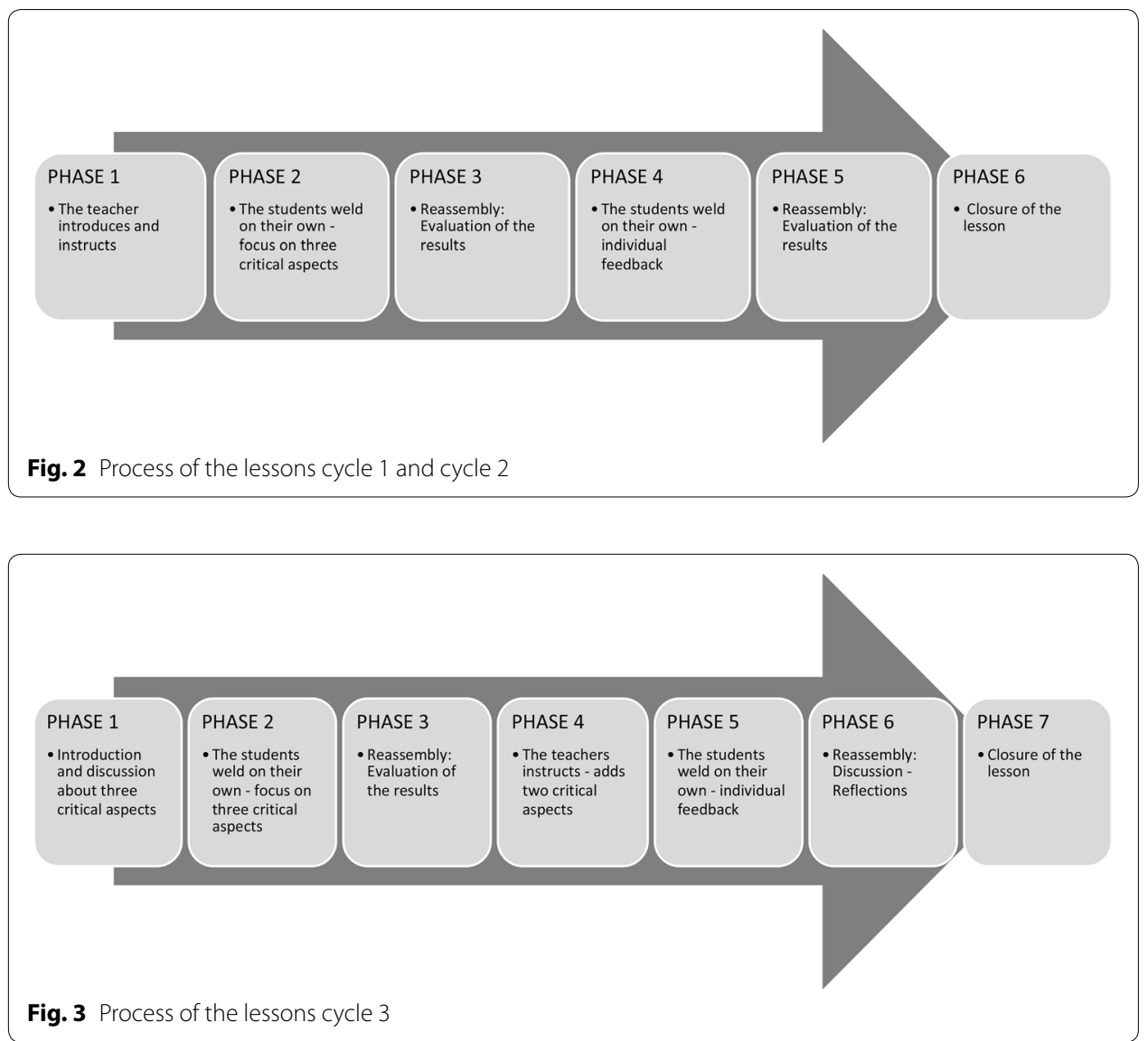

in detail about various aspects that are relevant when learning to TIG-weld, and he is now about to instruct the students on how to TIG-weld. Initially, the three students who participate in the teaching stand in front of the teacher, and when it is time for the teacher to weld in sharp situation, each student is instructed, in turn, to stand behind the teacher when he is welding, on the teacher's right side-with the purpose of letting the students get a good view of the welding act. The instruction itself has clear elements of teacher modelling (Asplund and Kilbrink 2018), which means that the teacher shows how to weld with his body, while he through verbal interaction tells what he is doing and what to think about in order for the work to be successful.

So, in our first example, the teacher $(\mathrm{T}=$ Teacher) is now interacting more closely with one of the students, Stefan (S), when he is instructing how to TIG-weld, and he is focusing on several critical aspects during this instruction, where the melt is one of those critical aspects. When modelling how to weld, the teacher thus tells the student what to do, and how to do it, and when he then orients towards the melt, he does that in the following way: 


\section{Excerpt 1A (the teacher instructs): Now you can see}

1. T: nu ser du stefan att e: e: smältan är skapad va Now you can see that the melt is created right

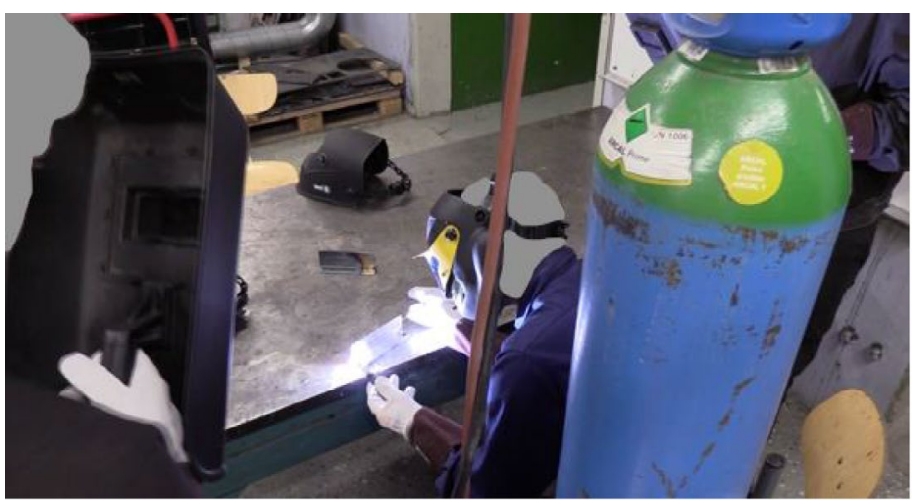

2. S: ((leans forward to the teacher $))$

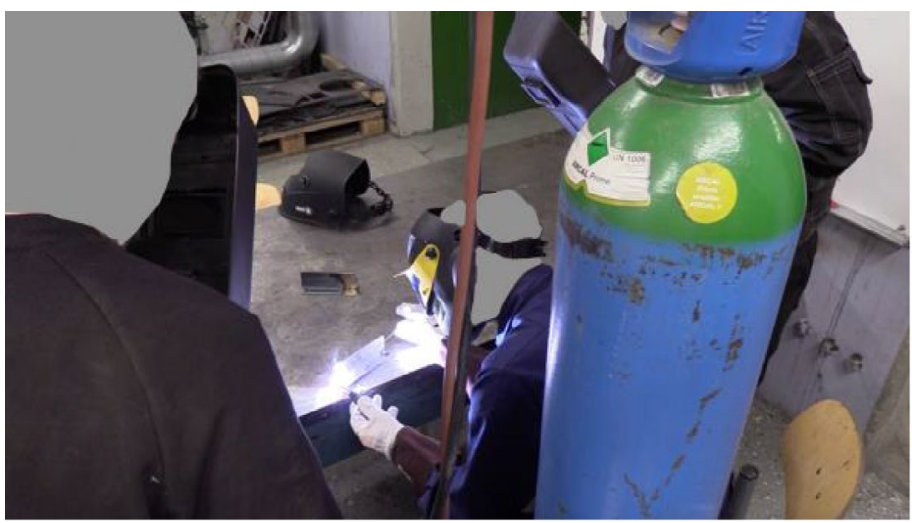

3.

ja

In line 1 , the teacher formulates a tag question that indicates that he strongly believes the student can see the melt being created, and that he by constructing this question invites the student to decide on the truth of the proposition in the statement (Hayano 2013). The student then leans forward towards the goods that it is welded on and then he confirms the teacher's question when he says "yes" in line 3. The example shows how the teacher informs the student that the melt is already created and that the student confirms that he can see the melt. What is being taught is thus about seeing the melt, where the melt is oriented to as an own subordinated OoL in relation to TIG-weld with an indirect and direct aspect. The indirect OoL is then the ability to see, which is connected to the direct OoL the melt.

The example is also a typical teaching situation where the teacher initiates and is the one who instructs (through the use of both embodied and verbal communicative resources) and where the student positions himself as a student who displays an interest to learn: he looks at what the teacher is doing, leans forward toward the melt in response to the teacher's question, and then confirms it. 


\section{Ideas for the next cycle}

As a result from the first cycle, we decided to put three more central critical aspects into the foreground (the melt, the movement with the additive material and the length of the arc). The teacher should then try to incorporate CAVTA more systematically as a base for the teaching by focusing on those three critical aspects of TIG-welding more explicitly in the teaching situation, aiming for a clearer focus on the OoL to make a TIG-weld. It was also decided that the teacher should try to establish a shared understanding of the OoL by encouraging the students to verbalise what happens during the act of TIG-welding. In the following examples, we will delimit our focus on the critical aspect-the melt - in the closer and more detailed analyses.

\section{Cycle 2}

The next example is an excerpt from cycle 2. The situation shown below is identical to the one above in that we have entered the stage of the teaching (Phase 1, Fig. 2) when the teacher is to instruct the students on how to make a TIG-weld. On this occasion, there are three new students who participate in the teaching. When we go into the example, the third student is in turn to watch close up when the teacher is welding. During the welding, the teacher $(\mathrm{T})$ tells the student $(\mathrm{S})$ what to do, and how to do it, and this time he works a lot with contrasting the critical aspects the movement with the additive material, and the length of the arc. Regarding the critical aspect the melt, contrasting as a pattern of variation is not used. Instead, the teacher orients towards the ability to discern the melt by asking the student to tell "when" he "can see the melt":
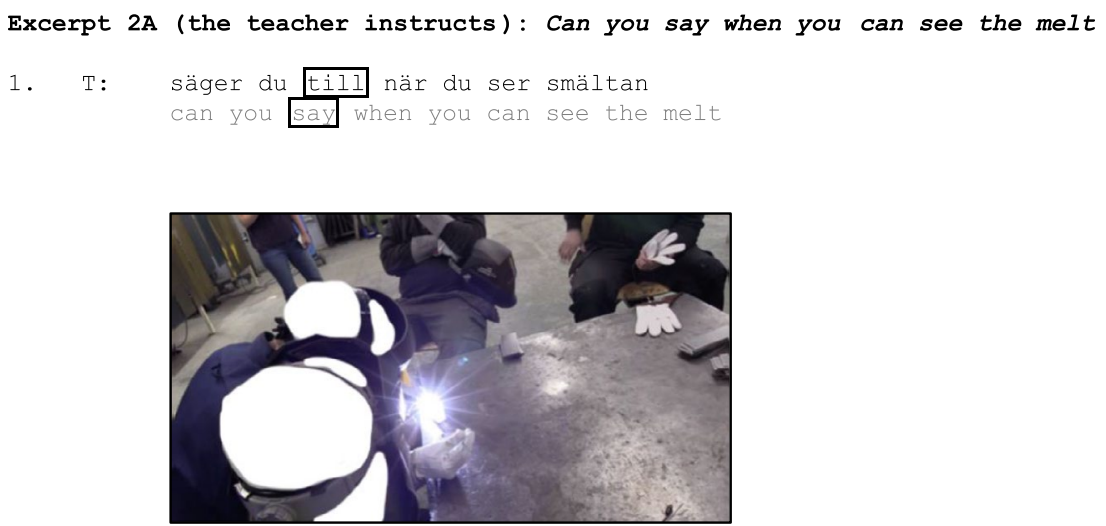

2. S: ja (5.5) dä:: r:

yes $(5.5)$ the: : $r: e$

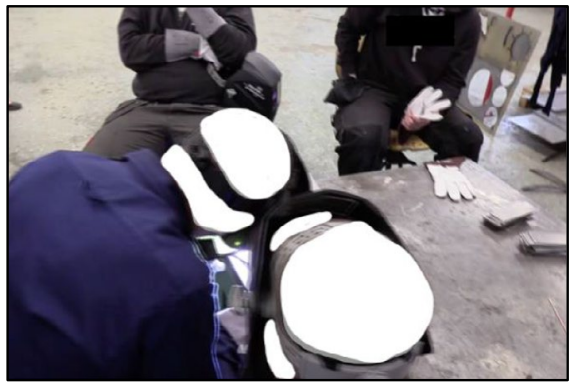

3. $\mathrm{T}$ : $\mathrm{n}: \mathrm{u}$ börjar den komma ja

now it's coming yes 
In line 1 the teacher invites the students to "tell" when he "can see the melt". By using the conventionalised request form "can you" the teacher treats his request as noncontingent; that is he claims the right to have his request granted (cf. Curl and Drew 2008), which he also gets, given by the student's affirmative answer in line 2: "yes". Unlike the previous example above (Excerpt 1A from cycle 1), the teacher's request is formulated in such a way that the student is given the opportunity to discern the melt on his own. When the melt is in focus in the teaching process, the melt is foregrounded as an own OoL, with a direct and indirect aspect, just like in the first cycle. In contrast to the first cycle, however, the direct OoL is about discerning the melt itself-not just confirming when seeing the melt.

The student is thus tasked to show the ability to discern the melt and identify when he can do it. This gives the teacher the opportunity to gain knowledge about the student's ability to carry out the above tasks. This differs from the first example (Excerpt $1 \mathrm{~A}$, above) where the teacher cannot know for sure if the student can or cannot see the melt, because the conditions there were already given: the teacher had seen the melt-it already existed-and the student had to agree with that statement. This means that the direct object-the melt-is held constant, but that the indirect object is shifting from seeing the melt (when the teacher shows it) in cycle one, to discern it and to tell when one can see it in cycle two.

After the teacher's request and the student's affirmative response, a silence of $5.5 \mathrm{~s}$ follows. The student then says "the::r:e". This is a rather elaborated prolonged "there" which indicates that he says the word while the melt begins to develop. This interpretation is reinforced by the teacher's confirmation "no:w it's coming yes", in line 3 . The melt is about to happen-i.e. now it is possible to start distinguishing it. The student's response to the teacher's request, and the teacher's follow-up of the student's answer to line 3 indexes a shared understanding of what they are looking for and talking about; the melt. The silence of just over $5 \mathrm{~s}$ also testifies that the melt does not exist when the teacher asks the student to say when he sees it. In one respect, the situation can therefore be described as a situation where the melt itself is contrasted; first no melt exists, but after a while it arises and becomes visible. The melt can thus assume different states; from not existing at all, to existing and to adopting different shapes. What happens in the example is that the student tells the teacher when he begins to distinguish the melt, and the teacher's reaction can be interpreted as that the melt is now beginning to "come", but that it has not yet properly adopted its correct value. In this part of the lesson, when distinguishing the melt is treated as an OoL itself, there are indications of critical aspects important to know how to discern the melt, but those are not oriented to, and thus not made visible in the interaction.

Furthermore, the example illustrates a changed participation (cf. Sahlström 2009) concerning the teacher's way of teaching. In excerpt $1 \mathrm{~A}$ above (cycle 1), the student is encouraged to confirm what the teacher is already seeing, i e the melt is already existing. In excerpt $2 \mathrm{~A}$ (cycle 2) however, the student is offered a possibility to display the ability to discern the melt himself, and also to tell when he sees that the melt is arising, something that we interpret as a result of the teacher's way of incorporating CAVTA as a base in the teaching. 


\section{Interaction-the students are welding on their own}

At the time when we get into the third excerpt (the second example from cycle 2) the teacher has finished his instruction, and the students are in each welding booth where they are trying to TIG-weld on their own for the very first time at school. During this phase (Phase 2, Fig. 2) in the teaching, the teacher moves between the booths and the students when they are welding, and also interacts with them continuously about their welding.

One element of the interaction, and which the teacher sets into play with all the students, is the highlighting of the three critical aspects which were selected as more central into cycle 2: the melt, the movement with the additive material and the length of the arc. While there is a more explicit teacher orientation towards contrasting the critical aspects the movement with the additive material and the length of the arc, the orientation towards the critical aspect the melt appears to be somewhat more diffuse in the interaction with all students. In the example below (Excerpt 2B), one of the students (S) has just been asked to contrast the movement with the additive material which he has done in a way that the teacher (T) finds satisfactory, after which the teacher orients himself towards the critical aspect the melt as follows:

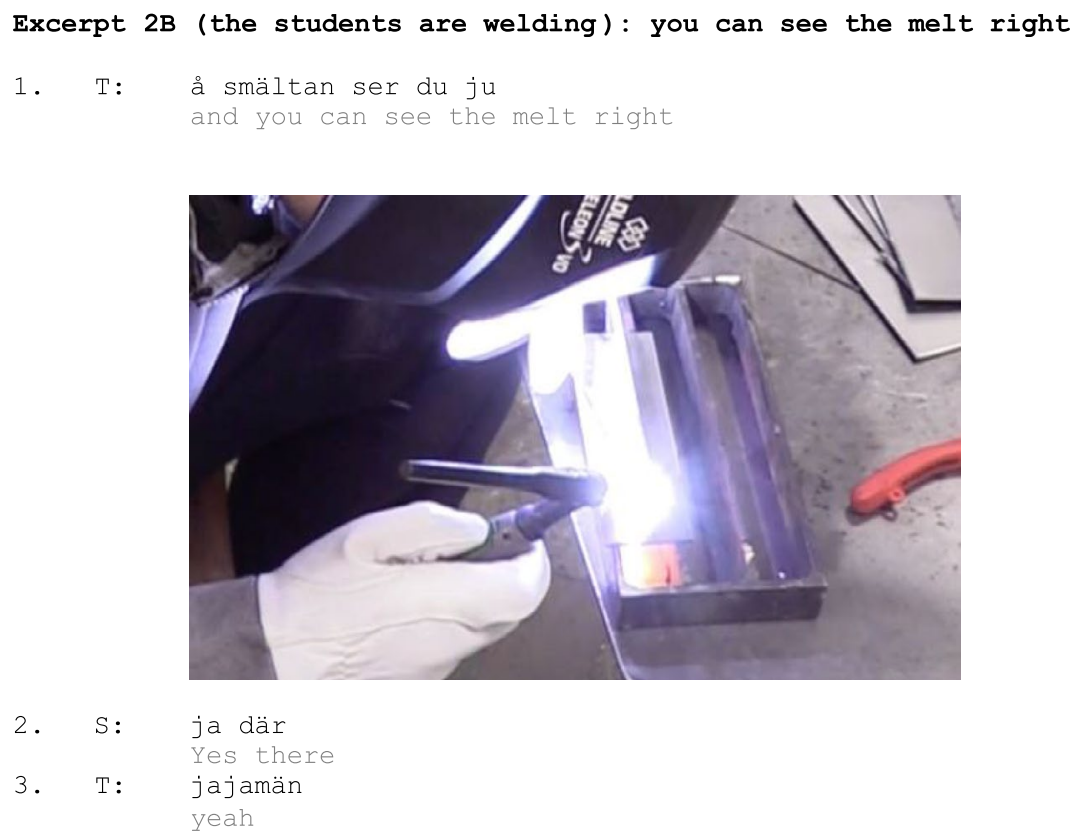


Here we can see that the teacher's question in line 1 takes the same expression as the one he asks the student during the instruction in excerpt $1 \mathrm{~A}$. At the end of the turn, the teacher uses the short Swedish adverb "ju", which is used to indicate a common knowledge or experience (see Heinemann et al. 2011), thus the turn is constructed as a tag question ("and you can see the melt right") through which he displays that he believes that the student can see the melt, and thus seeks confirmation from the student that he does. The student immediately confirms the teacher's question by answering "yes there", but does not point to or show in any way where the melt is. The teacher does not encourage the student to clarify, either. Instead, he leaves the melt as a topic, and orients himself towards another critical aspect. This means that in this part the indirect OoL is back to where it was in the first cycle-and relates to "seeing" the melt (when the teacher tells him to).

\section{Ideas for the next cycle}

As a result from the second cycle, we decided that the phases during the whole workshop lesson would be slightly changed. For example, this meant that the teacher-led instruction during the introduction (Phase 1; Fig. 2) would be completely removed; in favour of an introduction where teachers and students together instead conducted a dialogue on the three critical aspects that were focused in cycle 2 (see Phase 1, Fig. 3). Furthermore, in phase 6 (Fig. 3), the students would be given more space to verbalise their experiences of and perceptions of what they learned during the pass (also to ventilate any difficulties etc.). In addition, when analysing the second cycle it emerged that the melt can be oriented to as an own OoL (see also the analysis of the excerpt $2 \mathrm{~A}$ above) in the teaching situation. Then it has its own critical aspects, concerning for example the colour and the shape of the melt. In relation to finding and defining critical features of the melt, a teaching strategy based on CAVTA were planned for, in which the students would be given the opportunity (both in the introduction and when welding on their own in the welding booth) to try to verbalise what happens when the melt arises and begins to exist and when it, as a critical aspect of making a TIG-weld, is adopting its right value (its critical feature).

\section{Cycle 3}

Next, three examples will be used to concretise the outcome of the third cycle. In the first example, the teacher and the students are in the first phase of the teaching (Fig. 3) and we enter the example when the teacher $(\mathrm{T})$ is orienting towards the melt by turning to one of the students, Noah $(\mathrm{N})$, and asking him explain what the melt is: 

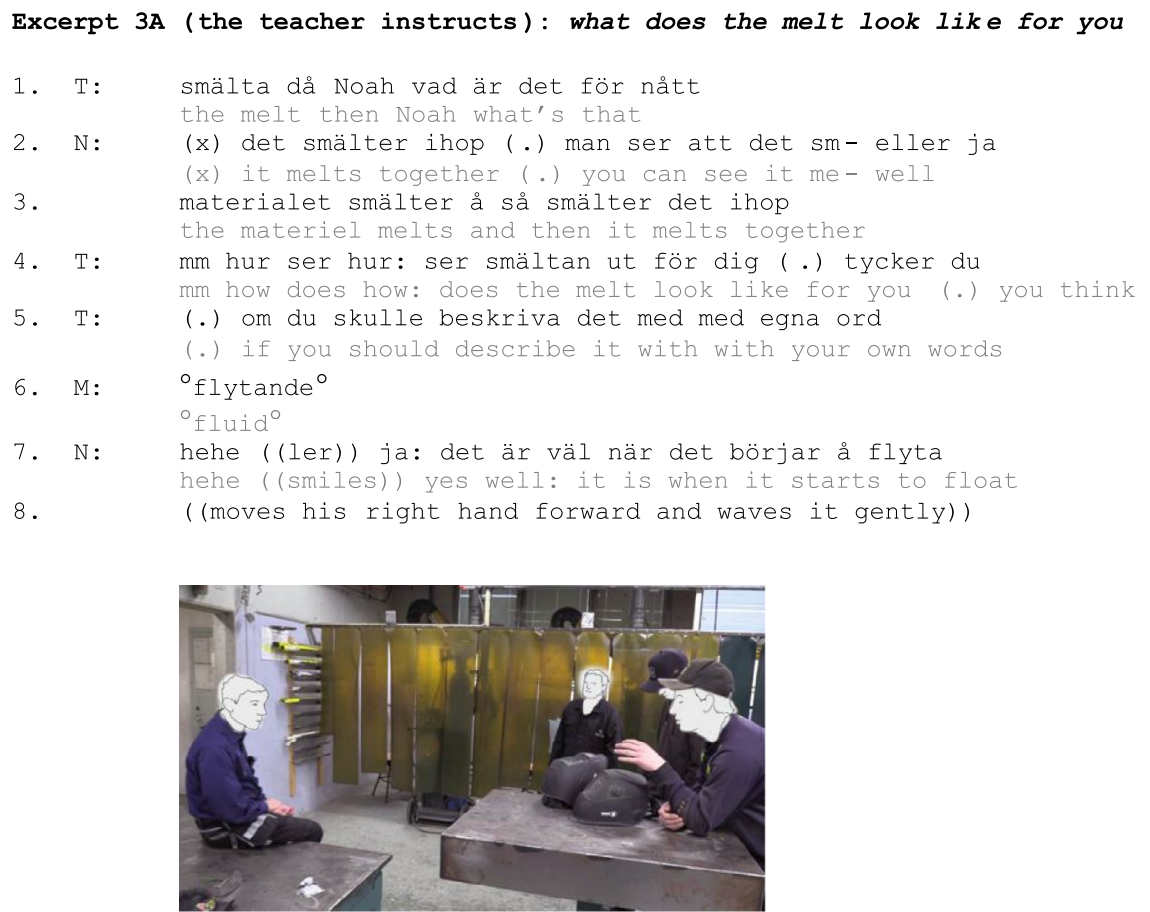

9. T: det börjar å flyta ja va sa du Mi chael

it starts to float yes what did you say Michael

10. M: jag sa det flytande ((nickar mot Noah)) (x)

11. (rinner) ( $x$ )

12. T: det blir ju nästan: som en liten: pöl va

it gets like almos:t a littl:e puddle right

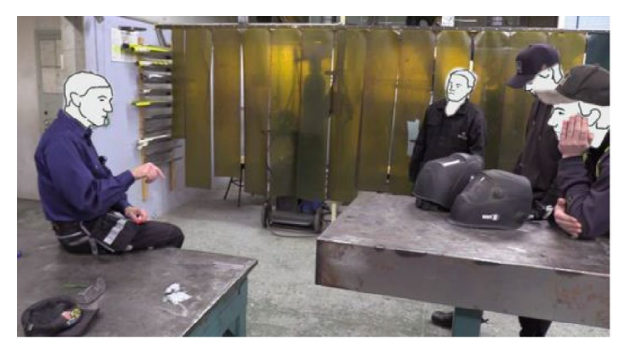

\footnotetext{
13. $\mathrm{M}: \quad($ nods $))$

14. N: ja

ja

yå (.) oke:j

well (.) oke:y
}

Just like in the previous cycles, the melt becomes an own OoL with an indirect and direct aspect when it is oriented to in the teaching situation. The direct OoL is still held constant-the melt-but the indirect OoL has changed again. In this situation the indirect aspect is about verbalising aspects of the melt or to put it in another way; to display an understanding of what the melt looks like. In this third cycle however, and in contrast to the first two cycles, the critical aspects of the melt are also verbalised and made relevant in the interaction. 
In response to the teacher's question, Noah says that it is about "the material melts and then it melts together" (line 3). After that, the teacher encourages Noah to develop his answer by asking him to describe with his "own words" what the melt looks like. Before Noah answers, however, Michael (M) says "fluid" in line 6 which is also a word that Noah uses with variation in his own description of the melt: "it is when it starts to float", he says while he also moves his left hand forward and lets it sway a little. This is also an example that in line with the CA-approach highlights the fact that speech and body mutually contextualises one another, providing public resources for the teacher and the students to organise relevant actions that, in concert with each other, contribute to the ongoing activity (Goodwin 2000, 2006; Streeck et al. 2011).

The teacher then repeats and confirms Noah's answer (line 9) and then turns to Michael and asks what he said. Michael then says something that probably contains the words "floating" (at the same time as he nods briefly towards Noah) and "floats", and then the teacher states that it becomes like "almost a little puddle right". The conclusion concludes with the Swedish word "va" which turns the statement into a form of question through which he also seeks a confirmation (Hayano 2013; Heinemann et al. 2011), something he also gets from Michael in line 13 (through his nodding) as well as Noah in line 14 ("yes").

Hence, in contrast to the previous cycles, the critical aspects of the melt itself is highlighted, helping the student to discern the melt as an own OoL. The critical aspects oriented to concern the shape and consistence of the melt and are highlighted by the students in this teaching sequence.

The example clearly illustrates how the teaching compared to previous cycles has changed in that the teacher and the students together try to verbalise what happens when the melt is taking shape. Using CAVTA as a way to let the students verbalise the melt is also something that is illustrated in the next example (Excerpt 3B). Here we meet Michael (M) when he is TIG-welding (Phase 2) for the first time and during his welding act he is instructed by the teacher $(\mathrm{T})$ in lines 1-4 to say what happens when the melt is taking shape and how he intends to act in relation to what he sees, with regard to making a TIG-weld: 
Excerpt 3B (the students are welding): tell me now what you see
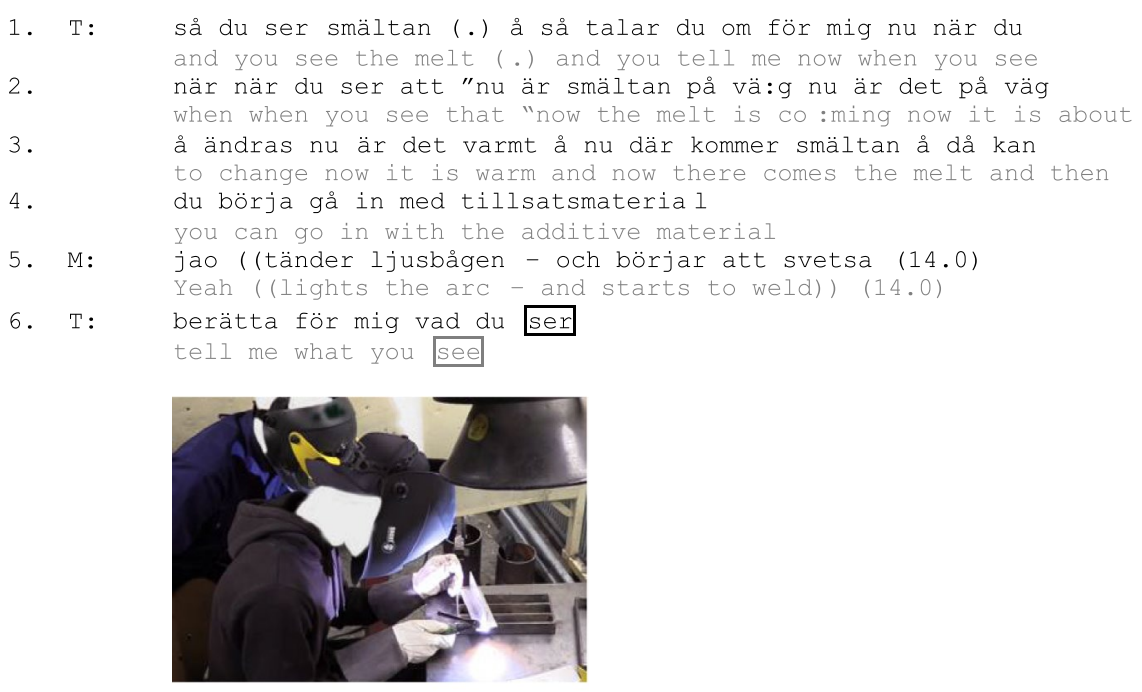

7. M: ja nu börjar det bli flytande här ((lutar sig framåt)) yes no it's gets fluid here ((leans forward))

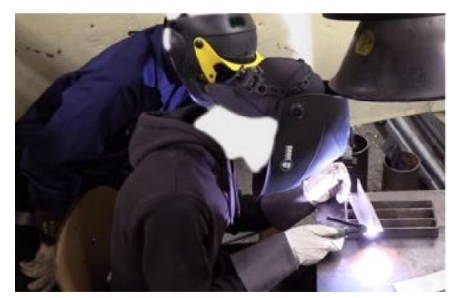

8. T:

vart har du flytande where do you have fluid

9. M: på där ((pekar med tillsatsmaterialet))

on there ((points with the additive material))

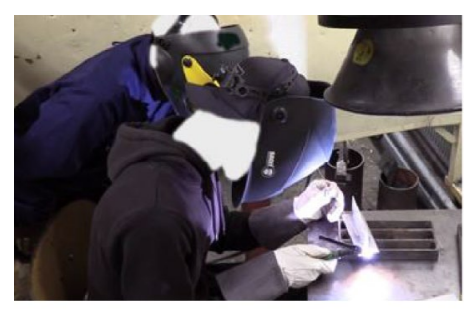
10. $\mathrm{T}$ :
på väggen liksom
on the wall like
11. M:
ja (.) nu smälter det ihop här
yes (.) now it melts together here
12. T:
där smälter det bra
there it melts good 
As soon as the teacher has encouraged Michael to tell what he sees (line 6), Michael says that "yes now it's starting to get fluid here" (line 7) while at the same time leaning forward with his upper body towards the weld. After this, the teacher asks Michael "where" he has "fluid", whereupon Michael answers "on there" (line 9) while pointing with the additive material against the melt. The teacher's follow-up question indicates that the teacher wants a clarification ("on the wall like") which he also gets through Michael's confirmation in line 12. After a short pause, Michael then says in line 12: "now it melts together here"; a comment that is also confirmed by the teacher.

When setting this example in relation to the corresponding teaching sequence in cycle 2 (Excerpt 2B above), it is clear that it is another teaching that takes shape in excerpt $3 \mathrm{~B}$, regarding the orientation against the melt compared to what we can see in excerpt $2 \mathrm{~B}$. It is therefore also possible here to speak in terms of a changed participation in the teacher's way of teaching, and as a concrete result of incorporating CAVTA in the teaching. Unlike what happens in excerpt $2 \mathrm{~B}$, the student in excerpt $3 \mathrm{~B}$ is given the opportunity to verbalise what happens when the melt takes shape (and not "just" tell the teacher when he sees it), and this also creates completely different conditions for the teacher to form an understanding of what the student says he sees, because the teacher-through his own presence-can see what happens when the student creates the melt. Furthermore, this teaching strategy also creates greater opportunities for the teacher to make a fair assessment of how well the student's demonstrated ability to distinguish the melt actually is, in comparison to the teaching strategy used in excerpt $2 \mathrm{C}$, because they are orienting themselves to a shared understanding of what they are looking at and talking about. In addition, by varying the indirect object of learning (the ability) relating to the melt; to see, discern, create and verbalise it; the student is offered a broader possibility to learn. Furthermore, they are verbalising the critical aspects of a melt, which not only broadens the possibility to understand the melt as a critical aspect of making a TIG-weld, but also increases the teacher's possibilities to access the students' understanding of the critical aspect-here and now. Verbalising their understanding creates increased opportunities and conditions for the teacher to meet the students and to be able to adapt the teaching in relation to the students' displayed understanding of the OoL.

In our last example we will see what it looks like when the teacher $(\mathrm{T})$, together with the students sum up the teaching pass (Phase 6). Each student has been able to verbally describe a critical aspect important to focus on when making a TIG-weld and in the excerpt below the melt is highlighted again: 


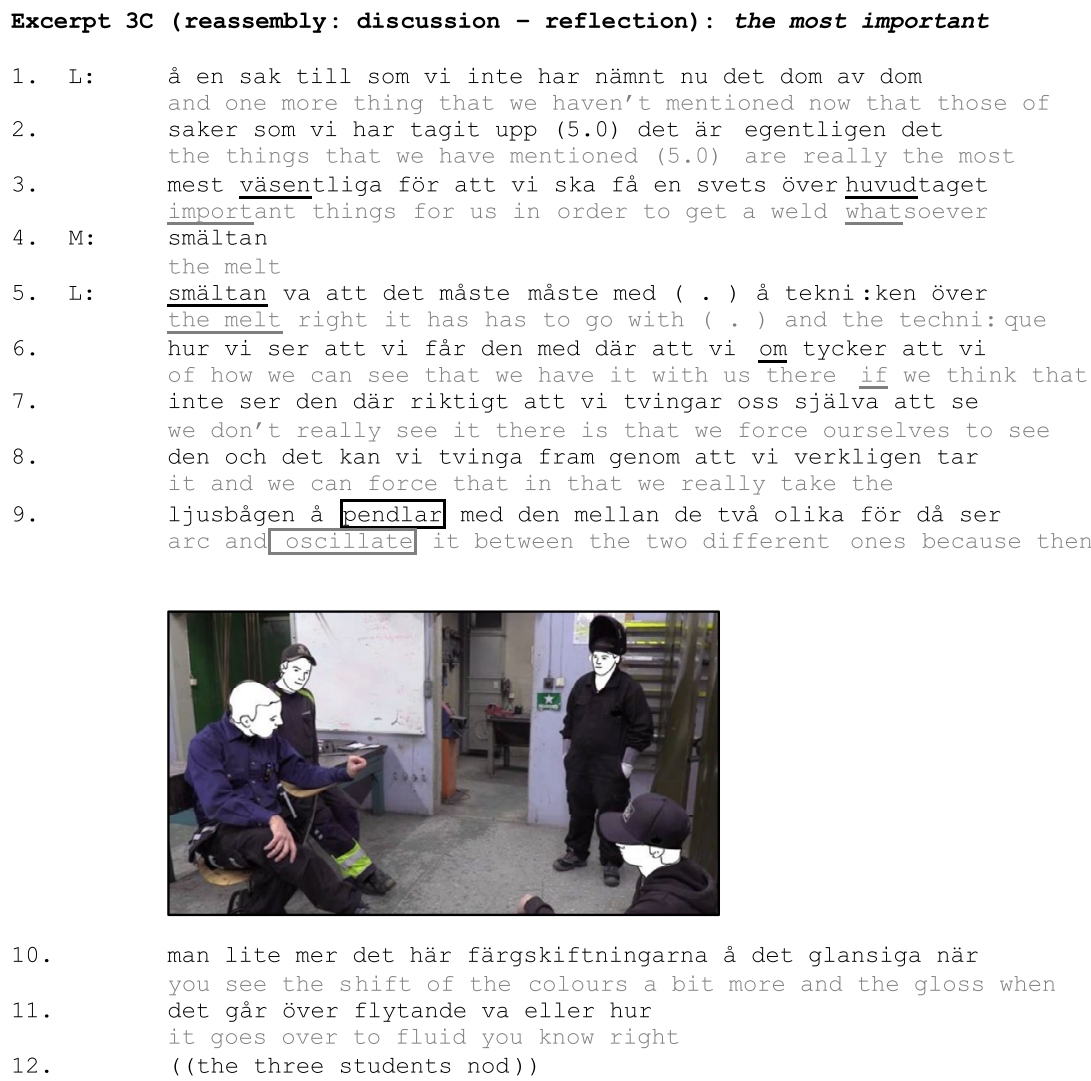

In lines $1-3$, the teacher formulates a turn through which he requests "one more thing" that they "have mentioned" which "really" is "the most important" in order to "get a weld whatsoever". Michael (M) is the student who constructs the answer (line 4) that the teacher requests (given the teacher's affirmative response in line 5). What happens next is that the teacher, through what could be called a mini lecture (cf. Asplund and Kilbrink 2018) in lines 5-11, develops a reasoning in which several aspects of the melt appear. First, it is about the fact that the melt "has to go with" and to find a technique by commuting the arc "between the two different ones" to "force" themselves to see that you have the melt with. Thereafter, the teacher develops a reasoning in which he explicitly explains how it looks when the melt is formed and when it takes shape when he says in lines 9-11: "then you see the shift of the colours a bit more and the gloss when it goes over to fluid you know right". The teacher finishes his turn by constructing a tag question, which is a question used to indicate a common knowledge or experience, through which he also seeks confirmation from the students; a confirmation he also gets (all the students nod).

These particular aspects, or this nuance of what happens when the melt is created and takes shape, and the teacher's verbalisation of this creation, are elements that were lacking in the teaching of the two preceding cycles. Even in the two previous cycles, the teaching was oriented towards the melt as an OoL when it was focused in the interaction that the students had to see (cycle 1), then to see and discern (cycle 
2). In cycle three, however, the melt is made relevant as an OoL with its own critical aspects, which are linked to the creation and development of the melt and which can be verbalised in terms of appearance and form; the melt changes its colour, becomes glossy and eventually it moves into liquid form. During cycle 3, the teacher also emphasises that the melt is also something that "has to go with"; i.e. it is not just about seeing, distinguishing and creating the melt, but it is also something that is linked to a movement forward and having with you when welding in the TIG-welding. Hence, it is first in the third cycle that the critical features of the critical aspects are made visible in the enacted teaching in a way that clearly displays what is important to understand in relation to the melt, which in turn is a critical aspect of the superior OoL to make a TIG-weld.

\section{Discussion}

Through the close and detailed analysis of how the teacher orients towards the melt in the teaching, it is possible to see how the teaching changes during the iterative cycles when the teacher gradually and systematically incorporates the theoretical framework CAVTA as a base for the teaching practice. More concrete, this change comprises for example of a movement where the melt has evolved from only being a critical aspect with the different values "being there" or "not being there" (i.e. right or wrong), to being an own subordinate OoL with its own specific critical aspects, such as colour and shape. The critical features of these critical aspects have been oriented towards and made explicit in the third cycle, which indicates that the OoL changes over time. Furthermore, this change highlights the complexity of an OoL and shows that the OoL has to be handled as dynamic and not fixed and predefined. Therefore, it can be developed over time as well as in the interaction between teacher and student (cf. Asplund and Kilbrink 2018; Kilbrink and Asplund 2018; Lo 2012).

In parallel with these results, the analyses have also shown that the indirect OoL (the ability), which is linked to the direct OoL the melt, has been varied to a greater extent the further into the cycles the teaching has come to. In the analysis of the interaction, we can therefore see how the abilities to see the melt, to distinguish it, to create it, to bring it, but also to be able to verbalise what happens when the melt is created, changes and adapts its right value-critical feature-is oriented to in the interaction there and then. This enables us to get sight of, and conceptualise, the complexity of the dynamic OoL to make a TIG-weld.

Hence, what the analyses, based on the CA-perspective, have shown is how the focus of on how a common understanding can be established in interaction and become an important didactic resource in the teacher's work on teaching how to learn to TIG-weld. Furthermore, the variation theory contributes with a specific focus on the learning content and adds concepts, such as learning objects, critical aspects, critical features, direct and indirect objects of learning and sharpens the teaching content of a Learning study project (cf. Lo 2012).

In the article we have thus shown not only how CAVTA can be used and integrated in practice in analyses of teaching and interaction, but also how it in a concrete way can be used as an analytical tool for teachers and researchers in a collaboration on how 
vocational teaching can be developed, and as a didactic tool for vocational teachers to plan, conduct and evaluate their own welding teaching. As a result from the detailed analyses we can see how the teacher, by using CAVTA as a base in his teaching, creates learning situations which enable an exchange between teacher and student through which they can use a number of different communicative resources in the interaction in order to claim, display and ascribe knowledge and understanding of how to see, to distinguish, to bring the melt, to create and verbalise the melt, to oneself, and one another. This can also be described as situations in which the teacher and the students together, and socially, construct a joint orientation toward doing learning to make a TIG-weld.

In addition, the variation of the indirect OoL the melt with its focus on different abilities creates better conditions for understanding the melt first as a subordinated OoL and then as a critical aspect of making a TIG-weld. These processes together provide increased opportunities for a more in-depth learning (cf. Marton and Booth 1997).

\section{Conclusion}

In this article, we have been able to distinguish how teaching to TIG-weld based on theories can be developed and the potential of bringing theories together in CAVTA and allowing these to be both theoretical and methodological starting points in an a Learning study where researchers and teachers interact and collaborate on the planning of teaching, data collection and analysis work on the basis of their respective and specific interpretation positions. In the analysis we can see concrete results of what happens when scientific theories are gradually incorporated into the teaching teacher's didactic approach, in a process over time when the welding teaching is planned, executed and analysed in three iterative cycles, inspired by the Learning study method. The approach as such has enabled spaces in the teaching where the teacher has made every effort to, in dialogue with the students, and in accordance with a CA perspective on learning (Sahlström 2011), tries to establish a common understanding of what is to be learned and how it is to be learned. But the approach has also, not least with the help of the variation theory (cf. Lo 2012; Marton and Tsui 2004), made it possible to conduct a teaching in which parts of the subject's specific content, which initially were not explicitly stated in the teaching, not only can be explicitly stated, but also specified in the moment, there and then.

These results are concrete expressions of movements towards teaching and learning processes where the so-called "tacit knowledge" is not only something that is made visible, but also something that is specified, through the simultaneous use of several different semiotic resources (cf. Kilbrink and Asplund 2018). More precisely, in the examples that we have focused on in this article, we can see how this takes place in relation to the orientation towards the critical feature of the OoL the melt. In order to verbalise this critical feature, the critical aspect the melt must be made into a separate, temporarily subordinate learning object with its own critical aspects with critical feature. In this specific case, the colour and the shape of the melt are made into critical aspects, which the teacher and the students together in the interaction with each other try to define and specify in order to get hold of the correct value of the melt's critical feature. However, these critical aspects are not highlighted in teaching by using different patterns of variation, something that Marton and Tsui (2004) emphasise as important when learning an 
OoL. This is something that could be developed in a fourth cycle in which the colour and the shape of the melt not only could be verbalised, but also contrasted.

In our study, the teaching is arranged in the sense that the teacher during the videorecorded lessons was able to concentrate on the three students who participated in the respective cycle. Usually, during the same teaching session, the teacher may have up to 20 students with different experiences, needs and abilities, which of course gives the teacher completely different conditions in order to be able to conduct a teaching approach like the one we have described and analysed in this article. Here we see a need for further studies where one can find forms for how similar teaching strategies focusing on establishing a shared understanding of an OoL could be used and developed in order to be applied even in larger teaching groups.

But not least, our findings suggest that there is a need for further Learning studies in the field of vocational education with an explicit pronounced interest in questions about the learning content. This can lead to a development where we can find forms for teaching where the specific content of the vocational subjects, a content which is sometimes a bit sloppy discussed in relation to the term "tacit knowledge" (cf. Lundgren and von Schantz 2012; Schaap et al. 2009), can be communicated, made visible, and specified.

\section{Abbreviations}

CA: Conversation Analysis; VT: Variation Theory; CAVTA: Conversation Analysis Variation Theory Analysis; OoL: object of learning; TIG: Tungsten Inert Gas.

\section{Acknowledgements}

Not applicable.

Authors' contributions

Both authors contributed substantially to this work. SBA and NK developed the methodological and theoretical framework of the paper. Data analysis for this paper was conducted by SBA and NK. Both authors discussed the manuscript at all stages. Both authors read and approved the final manuscript.

Funding

This study is financed by the Swedish Institute for Educational Research (ref no 2017-00056)

Availability of data and materials

All data analysed during this study are included in this published article.

Competing interests

The authors declare that they have no competing interests.

\section{Appendix}

\section{Transcript notations}

(2.0) Length in seconds of a pause

(.) A short untimed pause (less than 0,2 s)

(()) Contextual description and accounts

(x) An uncertain hearing of what the speaker said

Word Stressed syllable or word

${ }^{\circ}$ world $^{\circ}$ Degree signs indicate that talk is markedly quiet

: $\quad$ A prolonged stretch

- $\quad$ Hyphen after a word indicates a cut-off or self-interruption

Word Word Indicates the exact moment at which the screen shot has been recorded 


\section{References}

Andersson P, Köpsén S (2015) Continuing professional development of vocational teachers: participation in a Swedish national initiative. Empir Res Vocat Educ Train 7:7. https://doi.org/10.1186/s40461-015-0019-3

Antaki C (ed) (2011) Applied conversation analysis: intervention and change in institutional talk. Palgrave Macmillan, Basingstoke

Asplund S-B, Kilbrink N (2018) Learning how (and how not) to weld: vocational learning in technical vocational education. Scand J Educ Res 62(1):1-16

Brante G, Holmqvist Olander M, Holmquist P-O, Palla M (2015) Theorising teaching and learning: pre-service teachers theoretical awareness of learning. Eur J Teach Educ 38(1):102-118

Carlgren I (ed) (2017) Undervisningsutvecklande forskning: exemplet Learning study, 1st edn. Gleerups, Malmö

Curl TS, Drew P (2008) Contingency and action: a comparison of two forms of requesting. Res Lang Soc Interact 41(2):129-153

Drew P, Heritage J (2006) Editors' Introduction. In: Drew P, Heritage J (eds) Conversation Analysis, vol 1. Sage, London

Duranti A (1997) Linguistic anthropology. Cambridge University Press, New York

Emanuelsson J, Sahlström F (2008) The price of participation: teacher control versus student participation in classroom interaction. Scand J Educ Res 52(2):205-223

Filliettaz L (2011) Collective guidance at work: a resource for apprentices? J Vocat Educ Train 63(3):485-504

Goodwin C (2000) Action and embodiment within situated human interaction. J Pragmat 32(10):1489-1522

Goodwin C (2006) Human sociality as mutual orientation in a rich interactive environment: Multimodal utterances and pointing in aphasia. In: Enfield NJ, Levinson SC (eds) Roots of human sociality: culture, cognition and interaction. Berg Publishers, Oxford, pp 97-125

Hayano K (2013) Question design in conversation. In: Stivers T, Sidnell J (eds) Handbook of conversation analysis. WileyBlackwell, Malden, pp 395-414

Heinemann T, Lindström A, Steensig J (2011) Addressing epistemic incongruence in question-answer sequences through the use of epistemic adverbs. In: Stivers T, Lorenza M, Steensig J (eds) The morality of knowledge in conversation. Cambridge University Press, Cambridge, pp 107-130

Khaled A, Gulikers J, Biemans H, Mulder M (2016) Occurrences and quality of teacher and student strategies for selfregulated learning in hands-on simulations. Stud Contin Educ 38(1):101-121

Kilbrink N, Asplund S-B (2018) "This angle that we talked about": learning how to weld in interaction. Int J Technol Des Educ. https://doi.org/10.1007/s10798-018-9490-z

Kilbrink N, Bjurulf V, Blomberg I, Heidkamp A, Hollstein A-C (2014) Learning a specific content in technology education: learning study as collaborative method in Swedish preschool class using hands-on material. Int J Technol Des Educ 4(3):241-259

Ko PY (2018) Beyond labels: what are the salient features of lesson study and Learning study? Educ Action Res. https:// doi.org/10.1080/09650792.2018.1530126

Lave J (1993) The practice of learning. In: Chaiklin S, Lave J (eds) Understanding practice: perspectives on activity and context. Cambridge University Press, Cambridge, pp 3-34

Lo ML (2012) Variation theory and the improvement of teaching and learning. Acta universitatis Gothoburgensis, Göteborg

Lo LM, Marton F (2012) Towards a science of the art of teaching. Int J Lesson Learn Stud 1(1):7-22

Lucas B, Spencer E, Claxton G (2012) How to teach vocational education. A theory of vocational pedagogy. Centre for Skills Development, City and Guilds, London

Lundgren M, von Schantz Lundgren I (2012) Synliggörande av tyst kunskap i gymnasial yrkesutbildning. Nordic J Vocat Educ Train 2(1):1-12

Marton F, Booth S (1997) Learning and awareness. Lawrence Erlbaum Associates Inc, New Jersey

Marton F, Ling LM (2007) Learning from "the Learning study". Tidskrift för lärarutbildning och forskning 14(1):31-34

Marton F, Tsui AB (eds) (2004) Classroom discourse and the space of learning. Mahwah, N.J., Lawrence Erlbaum

Melander H, Sahlström F (2010) Lärande i interaktion [Learning in interaction]. Liber, Stockholm

Pang MF, Ling LM (2012) Learning study: helping teachers to use theory, develop professionality and produce new knowledge to be shared. Instr Sci 40(3):589-606

Postholm MB (2018) Teachers' professional development in school: a review study. Cogent Education 5(1):1-22

Rogoff B (2003) The cultural nature of human development. Oxford University Press, Oxford

Rusk F, Pörn M, Sahlström F, Slotte-Lüttge A (2015) Perspectives on using video recordings in conversation analytical studies on learning in interaction. Int J Res Method Educ 38(1):39-55

Sahlström F (2009) Conversation analysis as a way of studying learning - an introduction to a special issue of SJER. Scandinavian Journal of Educational Research 53(2):103-111

Sahlström F (2011) Learning as Social Action. In: Hall JK, Hellermann J, Doehler SP (eds) L2 interactional competence and development. Multilingual Matters, Bristol, pp 45-65

Sakai S, Korenaga R, Mizukawa Y, Igarashi M (2014) Envisioning the plan in interaction: configuring pipes during a plumbers' meeting. In: Nevile M, Haddington P, Heinemann T, Rauniomaa M (eds) Interacting with objects: language, materiality, and social activity. John Benjamins Publishing Company, Amsterdam, pp 339-356

Schaap H, de Bruijn E, Van der Schaaf MF, Kirschner PA (2009) Students' personal professional theories in competencebased vocational education: the construction of personal knowledge through internalisation and socialisation. J Vocat Educ Train 61(4):481-494

Schaap H, van der Schaaf M, de Bruijn E (2017) Interactions in vocational education: negotiation of meaning of students and teaching strategies. Stud Contin Educ 39(1):52-70

Schegloff EA (2007) Sequence organization in interaction: A primer in conversation analysis 1. Cambridge University Press, Cambridge

Serafini M (2018) The professional development of VET teachers in Italy: participation, needs and barriers Statistical quantifications and benchmarking in an international perspective. Empir Res Vocat Educ Train 10:3. https://doi. org/10.1186/s40461-018-0064-9 
SFS (2010:800) Skollagen. (Education Act)

Sidnell J (2013) Basic conversation analytic methods. In: Stivers T, Sidnell J (eds) Handbook of conversation analysis. WileyBlackwell, Malden, pp 77-99

Streeck J, Goodwin C, LeBaron C (eds) (2011) Embodied interaction: language and body in the material world. Cambridge University Press, Cambridge

Timperley H (2011) Realizing the power of professional learning. Open University Press, Maidenhead

\section{Publisher's Note}

Springer Nature remains neutral with regard to jurisdictional claims in published maps and institutional affiliations.

Submit your manuscript to a SpringerOpen ${ }^{\circ}$ journal and benefit from:

- Convenient online submission

- Rigorous peer review

- Open access: articles freely available online

- High visibility within the field

Retaining the copyright to your article

Submit your next manuscript at $>$ springeropen.com 